\title{
Unified Power Quality Conditioner with Electric Double Layer Capacitor
}

\author{
B. Han, H. Lee and J. Lee \\ Department of Electrical Engineering \\ Myongji University \\ Kyunggi-do 449-728, South Korea \\ Phone/Fax number:+82 31330 6366, e-mail: erichan@mju.ac.kr
}

\begin{abstract}
This paper proposes a new configuration of UPQC (Unified Power Quality Conditioner) that consists of the DC/DC converter and the electric double layer capacitors for compensating the voltage interruption. The proposed UPQC can compensate the reactive power, harmonic current, voltage sag and swell, voltage unbalance, and the voltage interruption. The performance of proposed system was verified through experimental works with a prototype. The proposed system can improve the power quality at the common connection point of the non-linear load and the sensitive load.
\end{abstract}

\section{Key words}

Voltage interruption, DC/DC Converter, Electric Double Layer Capacitor, super-capacitor, UPQC (Unified Power Quality Conditioner)

\section{Introduction}

As more sensitive loads, such as computers, automation equipments, and communication equipments, have come into wide use, the power quality is a big issue in both customer and utility company. Since these equipments are very sensitive for the input voltage disturbances, the inadequate operation or the fault of these loads brings about huge losses [1]-[3]. The elimination or mitigation of disturbances propagated from the source side and the other loads interconnected is critical for improving the operational reliability of these critical loads.

UPQC has been widely studied to eliminate or mitigate the disturbances propagated from the source side and the other loads interconnected [4]-[6]. UPQC has two voltage-source inverters of three-phase four-wire or three-phase three-wire configuration. One inverter called the series inverter is connected through transformers between the source and the common connection point. The other inverter called the shunt inverter is connected in parallel with the load. The series inverter operates as a voltage source, while the shunt inverter operates as a current source.

UPQC can simultaneously mitigate the voltage disturbance in source side and the current disturbance in load side. UPQC can compensate voltage sag, voltage swell, harmonic current, and harmonic voltage, and control the power flow and the reactive power. However, it cannot compensate the voltage interruption because it has no energy storage in the dc link.

This paper proposes a new configuration of UPQC that consists of the DC/DC converter and the electric double layer capacitors for compensating the voltage interruption. The operation of proposed system was verified through experimental works with a prototype of 20kVA rating.

\section{Configuration of proposed UPQC}

Fig. 1 shows the configuration of proposed UPQC, which additionally has a DC/DC converter and supercapacitors for compensating the voltage interruption. The energy in the DC link charges the electric double layer capacitors through the bi-directional DC/DC converter when the system is in normal operation. The energy in the electric double layer capacitors is released to the DC link through the bi-directional DC/DC converter when the voltage interruption occurs.

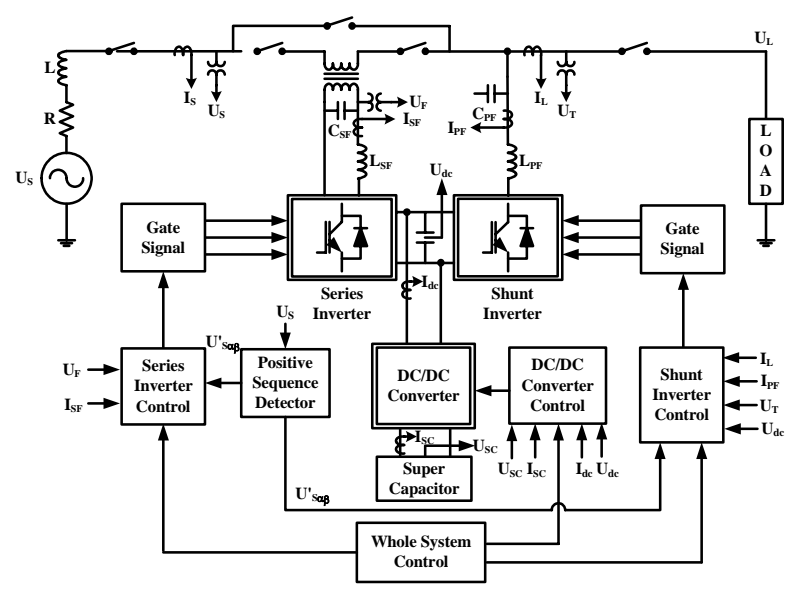

Fig. 1. UPQC system interconnected with energy storage

The control system has five major elements, which are system manager, positive sequence detector, shunt inverter control, series inverter control, and DC/DC converter control. The first four elements were implemented using a digital signal processor, while the last element was implemented using analog circuit. 
The system manager determines the operation mode depending on the level of source voltage, which was measured by the positive-sequence detector. The system works in normal mode when the level is maintained as $1.0 \mathrm{pu}$, and works in voltage sag or swell mode when the level is between 0.5 and $1.0 \mathrm{pu}$ or higher than $1.0 \mathrm{pu}$. It works in interruption mode when the level is lower than $0.5 \mathrm{pu}$.

In normal mode, the series inverter injects the zero voltage and the shunt inverter absorbs the current harmonics generated by the load. The DC/DC converter works in charge mode or standby mode depending on the voltage level of the super-capacitors.

In voltage sag or swell mode, the series inverter injects the compensating voltage to maintain the load voltage constant. The shunt inverter absorbs the current harmonics generated by the load and the DC/DC converter works in standby mode.

In voltage interruption mode, the series inverter is disconnected from the line and the circuit breaker is opened to isolate the source side. The shunt inverter starts to work as an AC voltage source. The DC/DC converter works in discharge mode to supply the energy stored in the super-capacitors to the load.

The positive-sequence detector extracts the positivesequence component from the disturbed three-phase source voltage. The algorithm for detecting the positivesequence component is described in reference [7].

The series inverter control compensates the voltage disturbance in the source side due to the fault in the distribution line. The series inverter control determines the reference voltage to be injected by the series inverter, using the algorithm described in reference [7].

The shunt inverter control has two functions to compensate the current harmonics and the reactive power in normal operation, and to supply the active power to the load during the voltage interruption. The first function was described in reference [7]. The second function is same as that of the power converter used in power system interconnection. The shunt inverter control has a selective switch as shown in Fig. 2, which works in current control mode or voltage control mode under the control of system manager.

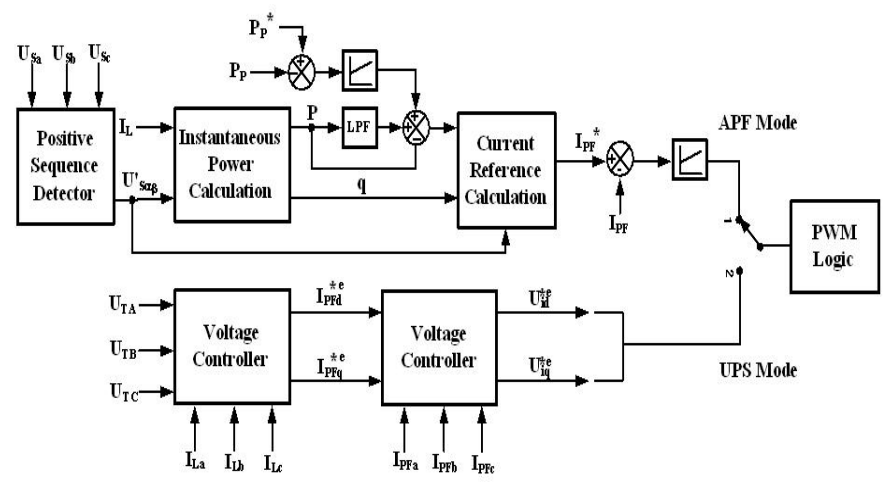

Fig. 2. Structure of the shunt inverter control

The DC/DC converter control works in charge mode or discharge mode selectively, depending on the direction from the system manager. In charge mode, the system manager monitors whether the voltage level of the supercapacitors exceeds the maximum operation voltage or not. If the voltage level reaches the maximum value, the DC/DC converter works in standby mode. In discharge mode, the system manager monitors whether the voltage level of the super-capacitors drops lower than the minimum operation voltage or not. If the voltage level reaches the minimum value, the DC/DC converter shuts down to stop supplying power to the load.

Fig. 3 shows the start-up procedure and interruption detection procedure of the proposed system. The operational flow explains the procedure to distinguish the voltage interruption from the voltage sag. The system manager handles the start-up procedure of whole system and the distinction of interruption mode.

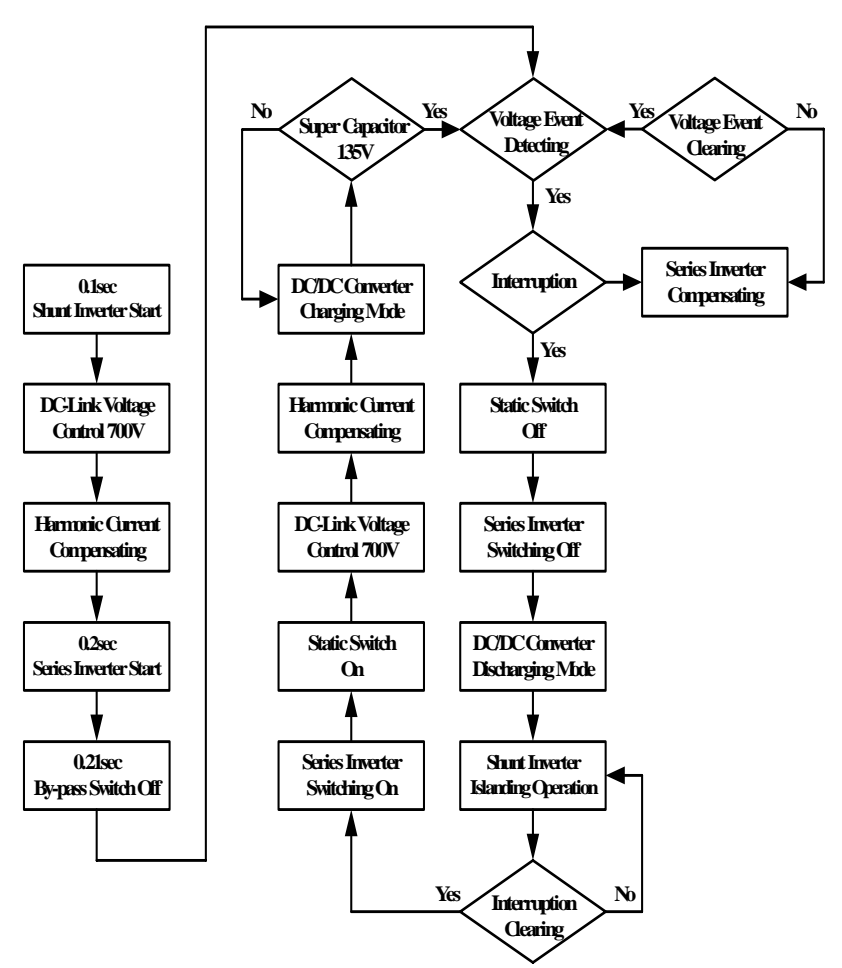

Fig.3. Start-up procedure and interruption detection procedure

\section{DC/DC Converter}

\section{A. Converter Design}

The DC/DC converter can operate in bi-directional mode using soft-switching scheme [8, 9]. The operation voltage of the super-capacitor bank is in the range between $115-135 \mathrm{~V}$, while the dc link voltage is about $700 \mathrm{~V}$. The ground point in dc link should be isolated from the ground point in the super-capacitor bank. The converter should have high current rating in bank side and high voltage rating in DC link side. Considering these requirements, a DC/DC converter with two fullbridges was selected as shown in Fig. 4 


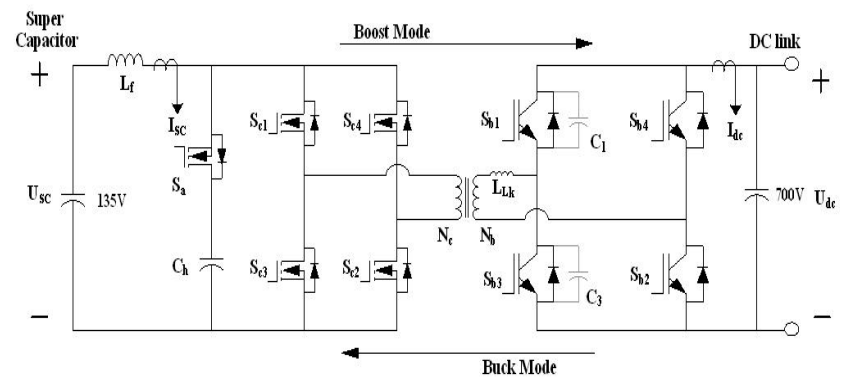

Fig. 4. DC/DC converter structure

A filter reactor is inserted between the bank and the full-bridge to reduce the ripple of charging and discharging current, which can reduce the lifetime of super-capacitors due to unwanted heat generation. The full-bridge in bank side works as a current-fed type, while the full-bridge in dc link side works as voltage-fed type.

The DC/DC converter boosts the super-capacitor voltage up to the nominal dc link voltage in discharge mode. The super-capacitor voltage is controlled between $115-135 \mathrm{~V}$, while the dc link voltage increases up to $700 \mathrm{~V}$. The switches $S_{c 1}$ and $S_{c 2}$ operate with a duty ratio of higher than 0.5 . The current through the inductor $L_{f}$ increases as all the switches are on conduction-state. The voltage overshoot can be suppressed by turning on auxiliary switch $S_{a}$ when two switches in face with diagonal opposition are on conduction state. The current through transformer rises linearly and its peak value becomes larger than the current through the boost inductor. The magnetic energy stored in the leakage inductance of transformer flows through the back-connection diode of off-state switch when the auxiliary switch turns off. So, the zero-voltage turn-on condition is provided.

The DC/DC converter decreases the nominal dc-link voltage down to the level of super-capacitor voltage in charge mode. When switch $S_{b 1}$ and $S_{b 2}$ turns on, the input voltage applied to the leakage inductance of transformer $L_{L k}$ increases the input current. The power in the primary side is transferred to the secondary side. The secondary voltage charges the capacitor Ch through the reverse-connected diode of auxiliary switch $S_{a}$. If the charging voltage is high enough to make the charging current zero, switch $S_{b 1}$ turns off. Switch $S_{b 3}$ turns on with zero-voltage scheme while the capacitor C1 is charged and the capacitor C3 is discharged. When auxiliary $S_{a}$ turns on, the voltage across the auxiliary capacitor affects the primary voltage of the coupling transformer. This voltage is applied to the leakage inductance $L_{L k}$ with reverse polarity. This makes the primary current zero and switch $S_{b 2}$ turns off with zerocurrent scheme.

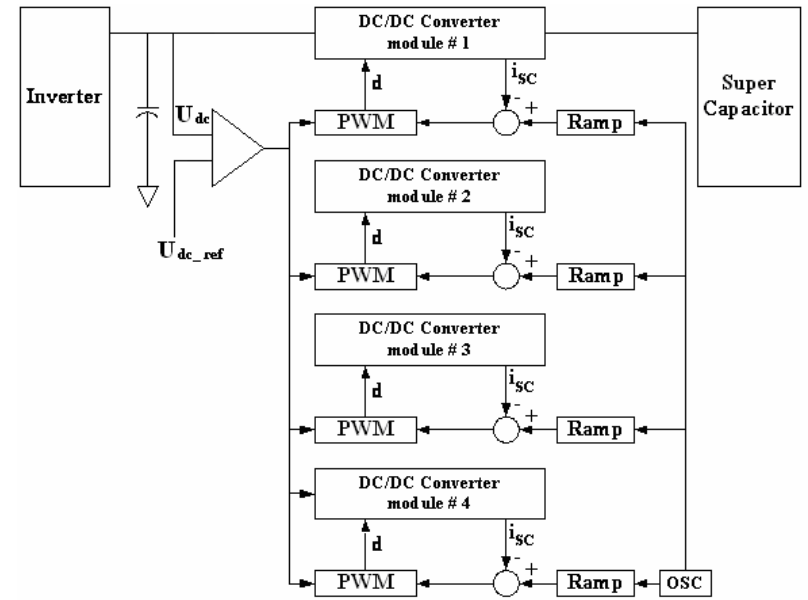

Fig.5. Four module parallel operation and PWM pulse interleaving

In design point of view it is not effective to build a $20 \mathrm{~kW}$ DC/DC converter in a single module due to the restriction in power rating of switching unit. Since supercapacitors operate at low-voltage large-current, the switching frequency is limited by the critical value of $\mathrm{di} / \mathrm{dt}$ which depends on the leakage inductance of the coupling transformer. So, when the converter is designed in a single module, the switching ripple of charging or discharging current is high. Therefore, the proposed DC/DC converter has four modules of $5 \mathrm{~kW}$ converter connected in parallel as shown in Fig. 5. When the multimodule is used, it is possible to expand the system rating and to increase the operation reliability. Also, the switching ripple of the charging or discharging current can be extremely reduced using the interleaving scheme of PWM switching.

\section{B. Controller Design}

The controller of DC/DC converter is comprised of main control, charging control, and discharging control as shown in Fig. 6. One function of main control is to select the charge mode and discharge mode according to the command from the system manager. The other function of main control is to monitor the operation of each converter module and to remove the module in fault. The main control also monitors the maximum and minimum charge or discharge voltage.

The DC/DC converter control was designed using OP amps and passive elements because the DC/DC converter requires higher switching speed in PWM than the shunt and series inverters.

The discharge control was designed to discharge the super-capacitors when the voltage interruption occurs in ac side. The discharge control consists of two control loops, which are the outer loop of voltage control and the inner loop of current control as shown in Fig. 7(a) and 7(b). 


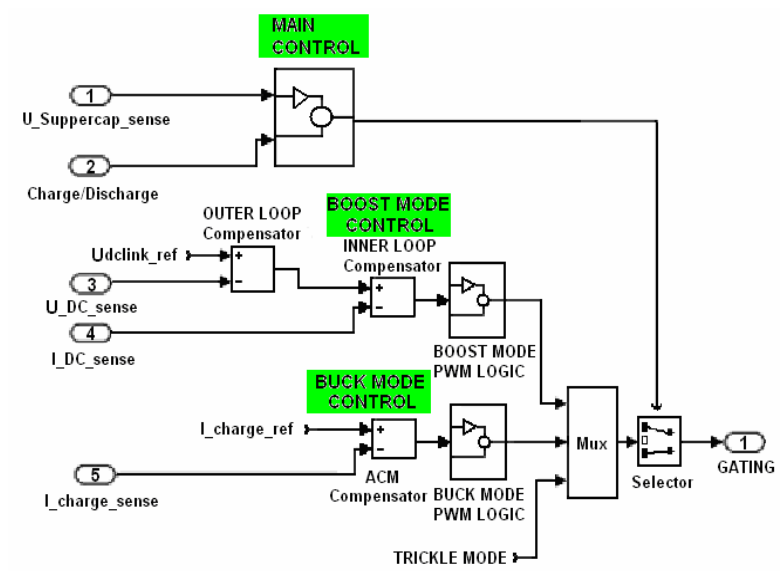

Fig.6. DC/DC Converter controller

The voltage control loop measures the DC link voltage and compares it with the reference voltage. The error passes through the RC circuit to calculate the reference current for the inner-loop current control. The inner-loop current control measures the discharge current in bank side and compares it with the reference current obtained from the outer-loop voltage control. The error passes through the RC circuit to calculate the duty ratio for the DC/DC converter module.

The charge control was designed to charge the supercapacitor in a slow speed in order not to make the DC link voltage change in normal operation. The charging operation is performed with $2 \mathrm{~kW}$ power rating for each module and stops when the bank voltage reaches $135 \mathrm{~V}$. The operation of charge control has the same configuration as that of the current control shown in Fig. 7(b).

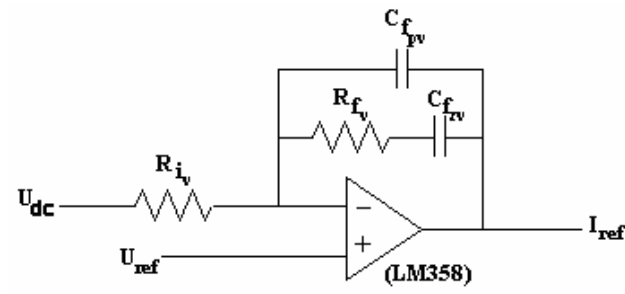

(a) Outer-Loop voltage control

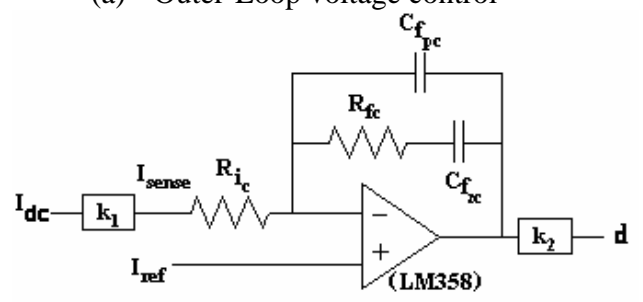

(b) Inner-Loop current control

Fig.7. Discharge control circuit

\section{Energy Storage Design}

The size of electric double layer capacitors is determined depending on the duration of voltage interruption and the size of load connected. It is assumed that the voltage interruption has duration of $2 \mathrm{sec}$ and the load has a power rating of $20 \mathrm{~kW}$. Therefore, total energy to be released during the voltage interruption is $40 \mathrm{~kJ}$.

The bank of electric double layer capacitors is designed considering three criteria, the expandability of storage capacity, the unbalance of unit voltage, and the current rating of each unit. HP1700P-0027A manufactured by Ness Company was selected as a basic unit for the energy storage bank. Table 1 shows the specification of selected electric double layer capacitor.

TABLE I

SPECIFICATION OF ELECTRIC DOUBLE LAYER CAPACITOR

\begin{tabular}{|c|c|}
\hline Parameters & Specification \\
\hline Capacitance & $1700 \mathrm{~F}$ \\
\hline $\begin{array}{ll}\text { ESR @25 } \mathrm{C} & \text { DC (100A) } \\
\text { AC }(100 \mathrm{~Hz}) & \end{array}$ & $\begin{array}{l}0.7 \mathrm{M} \text { ohms } \\
0.7 \mathrm{M} \text { ohms }\end{array}$ \\
\hline $\begin{array}{l}\text { Continuous operation } \\
\text { voltage } \\
\text { Peak operation voltage }\end{array}$ & $\begin{array}{l}2.7 \mathrm{~V} \\
2.85 \mathrm{~V}\end{array}$ \\
\hline Current rating & $360 \mathrm{~A}$ \\
\hline
\end{tabular}

The bank is designed so as to utilize the upper $25 \%$ of maximum storage capacity, considering the expandability of operation capacity by adding more capacitors. The maximum current flows through the capacitor bank, when it discharges the maximum power. The minimum voltage across the capacitor bank can be determined with the maximum discharge power and the current rating as the following.

$$
U_{\text {bank_min }}=40 \mathrm{~kW} / 360 \mathrm{~A}=111 \mathrm{~V}
$$

It is assumed that the capacitor is charged by $2.43 \mathrm{~V}$, which is $90 \%$ to the maximum charging voltage of $2.7 \mathrm{~V}$, for consideration of $10 \%$ margin. The lowest discharged voltage is determined to be $2.1 \mathrm{~V}$ using the following.

$$
U_{\text {unit_min }}=\sqrt{3 / 4} \times U_{\text {unit_max }}=2.1 \mathrm{~V}
$$

Therefore, the lowest discharge voltage and the minimum unit voltage determine the number of units to be connected in series as the following.

$$
N=U_{\text {bank_min }} / U_{\text {unit_min }}=53
$$

However, the bank was designed using total 56 units of capacitors for the purpose of safety margin.

\section{Experiment Result}

A prototype was built and tested to confirm the feasibility of actual hardware implementation. In order to simulate various fault cases, a source simulator using two inverters with DSP processor was built in a separate cabinet, which can generate the voltage sag, the voltage swell, and the voltage interruption for simulating all kinds of voltage disturbance in distribution system. UPQC was also built in a cabinet using two inverters with one solid-state switch and DSP processor. A $20 \mathrm{~kW}$ 
DC/DC converter with super-capacitors was built in a separate cabinet as shown in Fig. 8. There are four 5kW DC/DC converter modules and four racks of supercapacitor banks, where each module is connected with each super-capacitor rack in one by one manner. Both linear and non-linear loads are built for experimental work. Each load is designed for simulating the various load conditions.
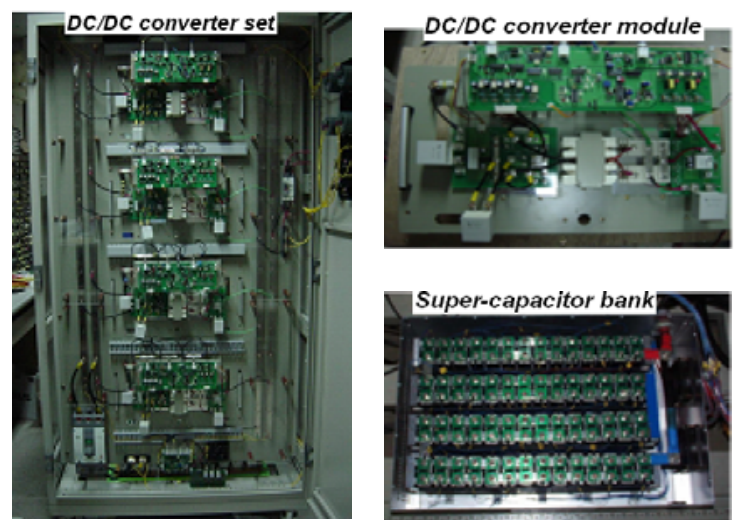

Fig.8. Hardware structure of DC/DC converter and supercapacitor bank

All the circuit parameters are exactly same as those used in computer simulation. All the experimental conditions are set up exactly same as the simulation conditions. Fig. 9 shows the compensation of harmonic current in the shunt inverter. Although there are some high-frequency harmonics, the experimental result is very close to the simulation result.

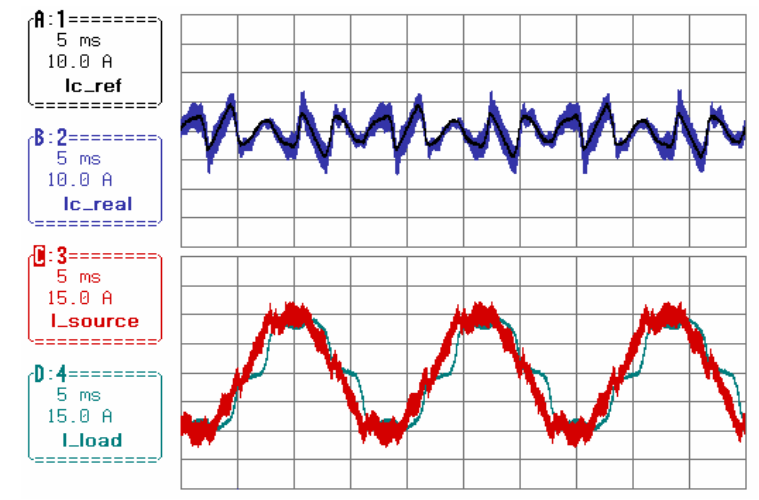

Fig.9. Active-Power Filter operation

Fig. 10 shows the experimental results when the unbalanced sag and swell occur. Both results are very close to the simulation results shown in Fig. 9 and 10.

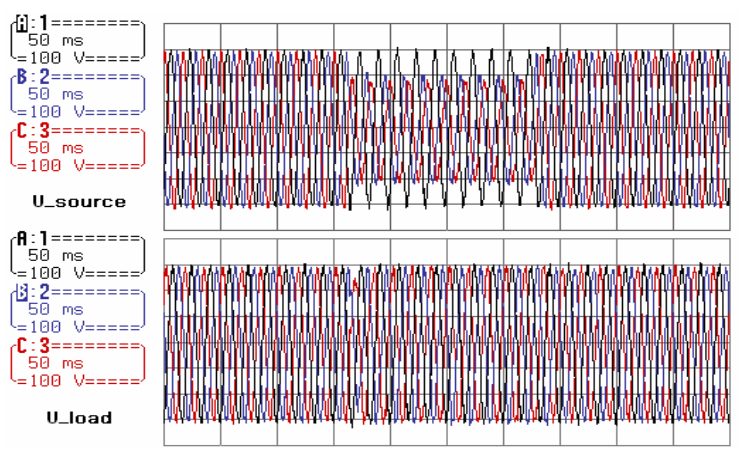

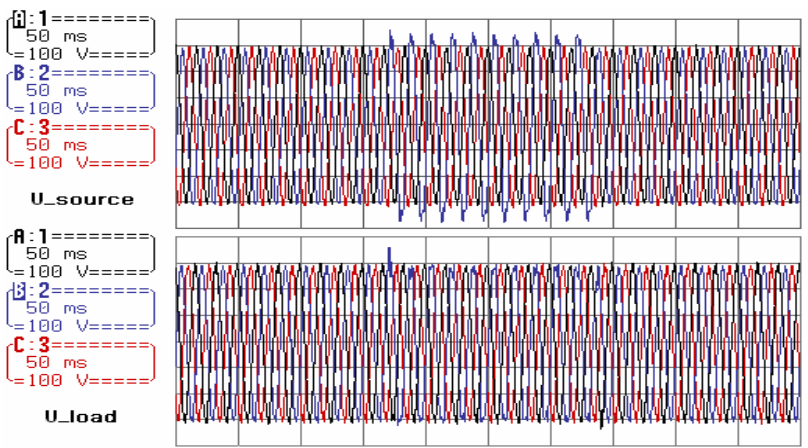

Fig.10. UPQC operation during sag or swell

Fig. 11 shows the experimental results when the voltage interruption occurs. The 1st and 2nd graph in Fig. 11(a) shows the source voltage and the load voltage in the voltage interruption for 2 seconds. The load voltage can be maintained as a constant value as expected. The 3rd and last graph shows the state signal for activating the solid-state breaker to isolate the source side.

Fig. 11(b) shows the active power variations during voltage interruption, which explains the power required in the load is provided by the shunt inverter of UPQC during the voltage interruption.

The 1st graph in Fig. 11(c) shows the voltage in the dc link, which is maintained at $680 \mathrm{~V}$ less than the normal DC link voltage $720 \mathrm{~V}$. But the control system increases the modulation index to maintain the output voltage properly. The 2nd, 3rd, 4th, and last graph shows the dc link current from each DC/DC converter module, which confirms that each module provides balanced constant current

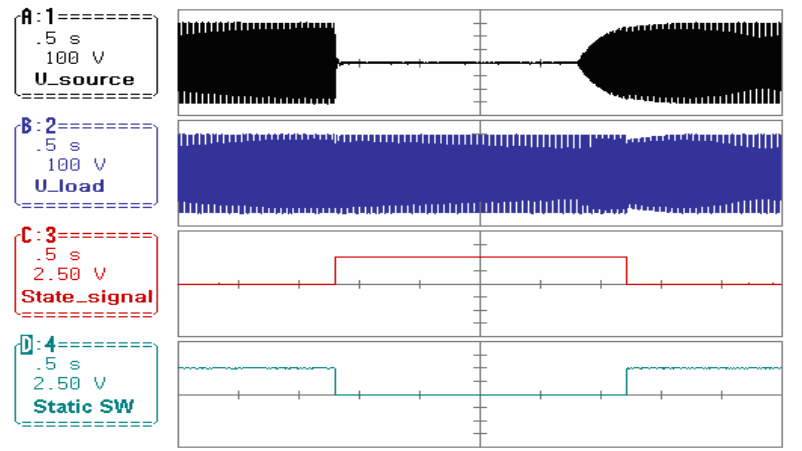

(a) Source voltage and load voltage, static switch gate signal

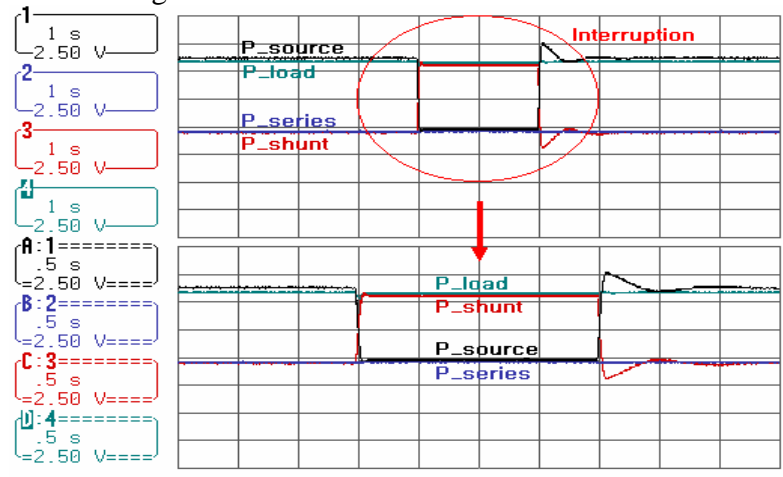

(b) Active power variation during voltage interruption 


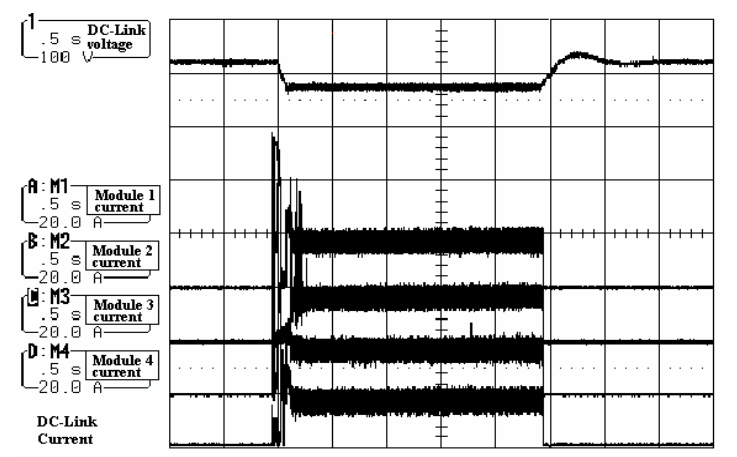

(c) DC-Link voltage and converter module output current

Fig. 11.UPQC operation during interruption

\section{Conclusion}

This paper proposes a new configuration of UPQC that consists of the DC/DC converter and the supercapacitors for compensating the voltage interruption. The proposed UPQC can compensate the reactive power, harmonic current, voltage sag and swell, voltage unbalance, and the voltage interruption.

The control strategy for the proposed UPQC was derived based on the instantaneous power method. The operation of proposed system was verified through experimental works with a prototype of $20 \mathrm{kVA}$ rating.

The proposed UPQC has the ultimate capability of improving the power quality at the installation point in the distribution system. The proposed system can replace the UPS, which is effective for the long duration of voltage interruption, because the long duration of voltage interruption is very rare in the present power system.

\section{Acknowledgement}

The research work described in this paper was supported by the Advanced Human Resource Development Program of MOCIE (Ministry of Commerce, Industry, and Energy) through the Research Center for Intelligent Micro-Grid in Myongji University.

\section{References}

[1] N. G. Hingorani, "Introducing Custom Power," IEEE Spectrum, June 1995, pp. 41-48.

[2] Jos Arrillaga, Math H. J. Bollen, Neville R. Watson, "Power Quality Following Deregulation", Proceedings of the IEEE, Vol. 88, No. 2, Feb 2000.

[3] Prodanovic. M, Green. T. C, "Control and filter design of three-phase inverters for high power quality grid connection", IEEE Trans. on Power Delivery, Vol. 18, No. 1, Jan 2003, pp. 373380.

[4] Hideaki Fujita, Hirofumi Akagi, "The Unified Power Quality Conditioner: The Integration of Series- and Shunt- Active Filters", IEEE Transactions on Power Electronics, Vol. 13, No. 2, March 1998

[5] Yunping Chen, Xiaoming Zha and Jin Wang, etc. "Unified Power Quality Conditioner (UPQC): The Theory, Modeling and Application", Power
System Technology, 2000 proceedings. Power Con 2000. International Conference on, vol. 3, pp. 13291333, 2000.

[6] M. Aredes, K. Heumann, E. H. Watanabe, "An universal active power line conditioner", IEEE Trans. on Power Delivery, Vol. 13, No.2, Apr 1998, pp.545-551.

[7] B. Han, B. Bae, S. Baek, G. Jang, "New Configuration of UPQC (Unified Power Quality Conditioner) for Medium-Voltage Application," IEEE Trans. on Power Delivery, Vol. 21, No. 3, pp. 1438-1444, July 2006.

[8] A. Bendre, S. Norris, D. Divan, I. Wallace, R. Gascoigne, "New high power DC/DC converter with loss limited switching and lossless secondary clamp”, IEEE Trans. on Power Electronics, Vol. 18 , No. 4 , July 2003, pp.1020-1027.

[9] J. Jacobs, A. Averberg, R. De Doncker, “A novel three-phase DC/DC converter for high-power applications”, IEEE Conf. on PESC 04, Vol. 3, 2025 June 2004, pp.1861-1867. 